\title{
Retrospective Research
}

\section{Cesarean Section Rate at Lumbini Zonal Hospital, Nepal: An Analysis Using the Robson Ten Group Classification System}

Bishnu Gautam, MBBS, MD, MPH ${ }^{\prime \#^{*}}$; Shree D. Acharya, MBBS, MD ${ }^{\prime \# ;}$ ishnu Prasad Sapkota, MHE²; Raut B. Batsal, MBBS, MD'; Laxmi Bhattarai, BDS, MS'; Maria Jose, MPH [MBBS, MPH] ${ }^{3}$; Kiran Paudel [Student] ${ }^{2}$

"Authors Share Equal First Authorship

'Department of Obstetrics and Gynecology, Lumbini Zonal Hospital, Butwal, Nepal

${ }^{2}$ Central Department of Public Health, Institute of Medicine, Tribhuvan University, Maharaajgunj, Nepal

${ }^{3}$ Independent Research Consultant, Cape Town, South Africa

\section{${ }^{*}$ Corresponding author}

\section{Bishnu Gautam, MBBS, MD, MPH}

Department of Obstetrics and Gynecology, Lumbini Zonal Hospital, Butwal, Nepal; Phone. (977) 9863930 I08; E-mail: bishnugautam6876@gmail.com

\section{Article information}

Received: September I ${ }^{\text {st }}, 2020$; Revised: September I2 ${ }^{\text {th }}, 2020$; Accepted: September 16 $6^{\text {th }}$, 2020; Published: October $16^{\text {th }}, 2020$

\section{Cite this article}

Gautam B, Acharya SD, Sapkota VP, et al. Cesarean section rate at Lumbini Zonal Hospital, Nepal: An analysis using the Robson Ten Group classification system Gynecol Obstet Res Open J. 2020; 7(I): 9-14. doi: 10.17I40/GOROJ-7-I54

\section{ABSTRACT}

\section{Background}

Caesarean section (CS) rates have increased globally. The World Health Organization (WHO) recommends the use of the TenGroup Robson classification as the global standard for assessing appropriateness of CS. Nepal has higher-than-global average rates of CS requiring further investigation into appropriateness.

Aim

This study aims to investigate the caesarean section rates at tertiary care center in Nepal and make analysis based on the group-10 classification.

\section{Methods}

A retrospective cross-sectional study was carried out from 2016 April -2017 March in Lumbini Zonal Hospital, Butwal, Rupendehi, Nepal. 3,817 women who birth over a 12-month period were analyzed using this classification. The caesarean rate, its indications were calculated and categorized into groups according to Robson's 10-group classification.

\section{Results}

Women with previous CS (Group 5) comprise the largest proportion (9.4\%) of the overall 26.41\% CS rate. The second largest contributor was a singleton nulliparous woman with cephalic presentation at term (6.6\% of total $26.41 \%)$. Caesarean section rates in single breech pregnancies were very high $(>65 \%)$. Robson's Group 5 was the highest contributors to overall CS rate contributing $35 \%$ of all C-sections, followed by Group $2(24 \%)$, and Group $1(13 \%)$.

\section{Conclusion}

The ten-group classification helped to identify the main groups of the subjects who contribute the most to the overall caesarean section rate. This study results suggest that women with previous CS are at risk for having another CS delivery in subsequent pregnancies and therefore there is an urgent need for a dedicated vaginal birth after caesarean section (VBAC) clinic to support this such women to ensure CS are only done when indicated. Furthermore, reducing the CS rate for nulliparous i.e. Group 1 and 2 would, in the long-term, also reduce the size of Group 5 in the future.

\section{Keywords}

Cesarean rate; Caesarean section; Robson's group classification. 


\section{INTRODUCTION}

G lobally, an estimated 19 births per 1000 population occur annually, ${ }^{1}$ out of which $19 \%$ are caesarean deliveries. ${ }^{2}$ Caesarean section (CS), a major surgical procedure, is essential to save the lives of neonates or mothers in certain fetal and maternal medical conditions. ${ }^{3,4}$ Considering that few birth complications demand a surgical intervention, a very small CS rate is often considered a reflection of the inadequate availability of essential surgical facilities. On the other hand, a CS rate above 16\% suggests CSs being carried out in medically non-warranted conditions. ${ }^{5-7}$ A CS rate higher than $16 \%$ is also linked with no additional maternal health benefits, ${ }^{5}$ but an unnecessary exposure to the adverse outcomes including anesthesia complications, internal organ injury, infection, thromboembolic disease, neonatal respiratory distress, and other complications of iatrogenic prematurity.

However, the optimal threshold for CS rates is debatable. An expert group coordinated by the World Health Organization (WHO) in 1985 suggested that a CS rate higher than $10-15 \%$ is not justifiable. ${ }^{10}$ This cutoff, despite being used globally as the optimal cutoff, is criticized for being not founded upon sufficient global evidence. ${ }^{5,11}$ Interestingly, a recent review of ecologic studies arrived at a similar threshold for CS rates. The study concluded that a CS rate of above $9-16 \%$ yields no maternal mortality saved hence, this range should be the optimal cutoff while evaluating CS rates of a population. ${ }^{5}$

Epidemiologic studies report caesarean section rates much higher than the suggested cutoff for most countries. Globally, $19.4 \%$ of all births occur via a $\mathrm{CS}^{2}$. This figure decreases to an estimate of $4.59 \%$ - an increment of more than $400 \%$ in 15-years-for Nepal. ${ }^{12}$ One study has reported a caesarean section rate in Nepal as high as $45.81 \%$ of the institutional births. ${ }^{13}$ Considering the high CS rate as a predictor of high preventable maternal mortality, routine auditing of the cesarean rates is essential.

Of the numerous techniques available for auditing CS rates, Robson's Ten Group Classification System (RTGCS) is the most preferred method. ${ }^{14}$ Using basic obstetric characteristics like parity, history of CS, gestational age, the onset of labor, fetal presentation and number of fetuses, RTGCS categories the CS in women into ten mutually exclusive and all-inclusive categories (Table 1). RTGCS as a standardized tool of caesarean section (CS) rates and indications, allows for clinical reviews, reflection and research at local, regional and national levels to better guide health system planning future care and enables comparisons of rate and indications as well. ${ }^{7}$ Recently, RTGCS has been recommended for use by the WHO and the International Federation of Gynecology and Obstetrics. ${ }^{15,16}$

This study analyzed caesarean section data from April 2016 to March 2017 in Lumbini Zonal Hospital, Western Nepal. The objectives were to compare the respective proportions of CS rates according to RTGCS categories and their contributing factors to identify major contributors to the cesarean delivery rates.

\begin{tabular}{|ll}
\hline $\begin{array}{l}\text { Table I. Obstetric concepts considered for classification of women } \\
\text { in the Robson's Ten Group Classification System }\end{array}$ \\
\hline \multicolumn{1}{c}{ Ethnicity } & \multicolumn{1}{c|}{ Caucasian } \\
\hline Category of pregnancy & Single cephalic pregnancy \\
\cline { 2 - 2 } & Single breech pregnancy \\
\hline Previous obstetric history & Single oblique or transverse lie \\
\hline & Multiple pregnancies \\
\hline Multiparous without a uterine scar \\
\hline Course of pregnancy & Multiparous with a uterine scar \\
\hline & $\begin{array}{l}\text { Spontaneous labor } \\
\text { Induced labor }\end{array}$ \\
\hline Gestation & Caesarean section before labor \\
\hline & $\begin{array}{l}\text { Gestational age in completed } \\
\text { weeks at the time of delivery }\end{array}$ \\
\hline
\end{tabular}

\section{MATERIALS AND METHODS}

\section{Study Setting}

This study was carried in Lumbini Zonal Hospital, Butwal, Rupandehi, Nepal. It is one of the oldest and the largest health facilities in Western Nepal. As a referral tertiary health facility, it provides services including super-specialized medical care.

\section{Study Design and Participants}

This study carried out a retrospective analysis of the deliveries carried out between 2016 April-2017 March. In the study period, 9261 deliveries were carried out in the hospital. Assuming 20\% CS rate according to global prevalence, $5 \%$ allowable error and a finite population correction to the calculated sample size, our plan was to capture the data of at least 3,695 women female study participants for this study.

A register of all female patients undergoing delivery in the hospital within a year was obtained from the labor room. First, a randomly selected patient file number was chosen and thereafter identification (ID) of women to be included in this study. Secondly, skipping every two consecutive IDs file numbers, 3,817 women were selected for inclusion in the study. Finally, detailed obstetric information was extracted from the medical records of each participant. The extracted information included parity, history of CS, gestational age, the onset of labor, fetal presentation and number of fetuses.

\section{Ethics}

This study is based on a secondary analysis of hospital records and did not include any face-to-face interaction with the women receiving safe motherhood service. The data were anonymized prior to extraction of hospital records. The study protocol was approved by Nepal Health Research Council.

\section{Statistical Analysis}

Data were entered in EpiData (version 3.1, The EpiData Associa- 
tion, Odense, Denmark). For statistical analysis, data were exported to $\mathrm{R}$ (version 3.3.3, R Project for Statistical Computing). First, the proportion of each type of delivery conducted in the study population was computed and thereafter the proportions of relative size of the group; CS rate; and contribution of each RTGCS group to all CSs were calculated.

\section{RESULTS}

Among the 3,817 women who had received delivery service in the study period, $2605(68.25 \%)$ had undergone normal delivery, 177 (4.62\%) had undergone instrumental delivery and 1008 (26.41\%) had undergone CS for delivery. For complete information, see Table 2 .

\begin{tabular}{|lcc|}
\hline \multicolumn{4}{|l|}{ Table 2. Obstetric Characteristics of Women } & Included in the Study \\
\hline Delivery Type & Number of Women & Percentage \\
\hline LSCS before labor (emergency) & 210 & 5.50 \\
\hline LSCS elective & 465 & 12.20 \\
\hline LSCS after labor & 360 & 9.43 \\
\hline Instrumental delivery & 177 & 4.62 \\
\hline Normal Delivery & 2605 & 68.25 \\
\hline Total & $\mathbf{3 8 1 7}$ & $\mathbf{1 0 0 . 0 0}$ \\
\hline
\end{tabular}

Table 3 shows the distribution of deliveries by RTGCS. When comparing the relative proportion of the studied deliveries (Table 3: Relative size of the group), highest proportion of deliveries in the hospital were in Group 1 (nulliparous, single cephalic, $\geq 37$-weeks, in spontaneous labour: $26.33 \%$ ) and in Group 2 (nulliparous, single cephalic, $\geq 37$-weeks, induced or CS before labor: $23.32 \%$ ). Similarly, Group 8 (all multiple pregnancies (including previous CSs)) and Group 9 (all abnormal lies (including previous CSs) ) made up $0.60 \%$ and $0.68 \%$ of all deliveries in the hospital respectively.

A comparative evaluation of CSs in each RTGCS group
(Table 3: CS rate) revealed that CSs were above 50\% in Group 5 (previous CS, single cephalic, $\geq 37$-weeks: $79.12 \%$ ), Group 6 (all nulliparous single breech: 68.18\%), Group 7 (all multiparous single breech (including previous CS): $71.43 \%$ ), Group 8 (all multiple pregnancies (including previous CS): 56.52\%), and Group 9 (all abnormal lies (including previous CS): $76.92 \%$ ).

A breakdown of CS in RTGCS group as the percentage of all CSs in the study period (Table 3: Contribution to all CS) points that Group 1 (nulliparous, single cephalic, $\geq 37$-weeks, in spontaneous labor: $13.89 \%$ ), Group 2 (nulliparous, single cephalic, $\geq 37$-weeks, induced or CS before labor: $24.80 \%$ ), and Group 5 (previous CS, single cephalic, $\geq 37$-weeks) were the top-three contributors of CSs carried out at Lumbini Zonal Hospital in the study period.

\section{DISCUSSION}

In this retrospective analysis of annual data on delivery conducted in Lumbini Zonal Hospital, it was found that $26.41 \%$ of the deliveries were conducted via CS. When compared across women of the different obstetric profiles, it was observed that CS rates varied from $6.22-79.12 \%$. With the documentation of the differential CS rate, this study identifies population groups that are at a higher than average risk of CS.

The study findings report a higher CS rate in the hospital compared to the global rate. Previous hospital-based studies on CS rates in Nepal report prevalence estimates of $4.59-45.81 \%{ }^{13,17,18}$ For comparison, the global CS rate is estimated to be $18.6 \%$ (range: 6-27.2\%) with a high rate in the most developed countries and a low rate in the least developed countries. ${ }^{19}$ Though there is an association between a country's improving economic conditions with increasing CS rates; high CS rates are associated with higher burden of poor maternal health outcomes. These include: increased risk of blood transfusion, hysterectomy, intensive-care unit admission, other severe maternal outcomes and preventable deaths if CS is carried out in medically unindicated conditions. ${ }^{?}$

\begin{tabular}{|c|c|c|c|c|}
\hline Group & Obstetric Characteristics & $\begin{array}{l}\text { Relative Size of } \\
\text { the Group }\end{array}$ & $\begin{array}{c}\text { Cesarean } \\
\text { Section Rate }\end{array}$ & $\begin{array}{l}\text { Contribution to all } \\
\text { Cesarean Section\# }\end{array}$ \\
\hline I & Nulliparous, single cephalic, $\geq 37$-weeks, in spontaneous labor & $1,005 / 3817(26.33)$ & $140 / 1005(13.93)$ & I40/1008 (13.89) \\
\hline 2 & $\begin{array}{l}\text { Nulliparous, single cephalic, } \geq 37 \text {-weeks, induced or cesarean } \\
\text { section before labor }\end{array}$ & $890 / 3817(23.32)$ & $250 / 890(28.09)$ & $250 / 1008(24.80)$ \\
\hline 3 & $\begin{array}{l}\text { Multiparous (excluding previous cesarean section), single } \\
\text { cephalic, } \geq 37 \text {-weeks, in spontaneous labor }\end{array}$ & $723 / 3817(18.94)$ & $45 / 723(6.22)$ & $45 / 1008(4.46)$ \\
\hline 4 & $\begin{array}{l}\text { Multiparous (excluding previous cesarean section), single } \\
\text { cephalic, } \geq 37 \text {-weeks, induced or cesarean section before labor }\end{array}$ & $402 / 3817(10.53)$ & $55 / 402(13.68)$ & $55 / 1008(5.46)$ \\
\hline 5 & Previous cesarean section, single cephalic, $\geq 37$-weeks & $455 / 3817(11.92)$ & $360 / 455(79.12)$ & $360 / 1008(35.72)$ \\
\hline 6 & All nulliparous single breech & $88 / 3817(2.31)$ & $60 / 88(68.18)$ & $60 / 1008(5.95)$ \\
\hline 7 & $\begin{array}{l}\text { All multiparous single breech (including previous cesarean } \\
\text { section) }\end{array}$ & $49 / 3817(1.28)$ & $35 / 49(71.43)$ & $35 / 1008$ (3.47) \\
\hline 8 & All multiple pregnancies (including previous cesarean section) & $23 / 3817(0.60)$ & 13/23 (56.52) & $13 / 1008$ (1.29) \\
\hline 9 & All abnormal lies (including previous cesarean section) & $26 / 3817(0.68)$ & $20 / 26(76.92)$ & $20 / 1008$ (1.98) \\
\hline 10 & $\begin{array}{l}\text { All single cephalic, }<37 \text {-weeks (including previous cesarean } \\
\text { section) }\end{array}$ & 156/3817 (4.09) & $30 / 156(19.23)$ & $30 / 1008$ (2.98) \\
\hline "Data are & proportion (percentage) & & & \\
\hline
\end{tabular}


Of the factors influencing caesarean section rates, human factors have a major contribution. For instance, in the United States, the risk of having a CS can increase by ten-folds depending upon which hospital a pregnant woman visits, ${ }^{20}$ and by three-folds depending upon which delivery nurse a woman is assigned to. ${ }^{21}$ However, no study in Nepal has assessed the role of human factors on the proportion of medically unindicated CSs till date.

This study observed that Group 1 and Group 2 were the top-two contributors of pregnant women whose data were analyzed in this study. Group 1 and 2 include nulliparous women who are a crucial population segment for the prevention of the index CS prior to women being exposed to higher risk of a CS in the later pregnancies. ${ }^{22}$ This observation is in partial conformity with other studies employing RTGCS classification which report Group 1 and Group 3 as the largest proportion of the study population. ${ }^{17,22}$

Women in Group 5, with a history of CS, constituted $11.92 \%$ of the women in our study. This finding is of importance as a woman who has already given birth with a CS is at a higher risk of undergoing either medically warranted or elective CS in her next pregnancy due to fear of complications. ${ }^{23}$ Though the proportion of women in Group 5 currently is not very high, it is likely to continue increasing as the CS rates in Nepal is on the rise, ${ }^{12}$ and increases in CSs in other groups ultimately drives an increase in Group 5. Control of CS rates in this group is challenging as a history of CS is an independent determinant of caesarean sections in subsequent pregnancies.

The rate of CS in Group 1, nulliparous single cephalic women with a gestation of $\geq 37$-weeks and spontaneous labor, was $13.93 \%$. CS rate for Group 2, nulliparous single cephalic women with a gestation of $\geq 37$-weeks and induced or CS before labor, was $28.09 \%$. To compare, a study from Central Nepal reports that $30.2 \%$ and $11.5 \%$ of CSs were done in women belonging to Group 1 and 2 respectively. ${ }^{17}$ Typically, Group 1 and 2 represent one of the population groups with the least risk of CS, assuming a low prevalence of medical conditions that warrant CSs. Our observations of a high CS in these groups provide valuable insight into the population segments to target for achieving control of unnecessary CS rates. Robson et al. report that for the control of CS, the focus should be on Group 1 and 2 if they bear a high rate of CS. ${ }^{24}$ Further research is needed to understand whether or not the high CS rates in Groups 1 and 2 is due to women's preferences and what can be done to address it.

Women with a previous history of CS had the highest rates of all RTGCS groups in this study. This observation is in conformity with the global evidence: both in the developed and developing countries: women with a history of CS prefer to avoid vaginal delivery in their later deliveries as the risk of uterine rupture and other maternal morbidities in vaginal delivery following CS is higher. ${ }^{25}$ However, vaginal birth following a previous cesarean section (VBAC) is associated with maternal health benefits and limited risks compared to a having another delivery by CS. ${ }^{26}$ The establishment of a dedicated clinic to counsel pregnant women during their antenatal checkup has been found to be successful at promoting VBAC rates. ${ }^{27}$ Piloting a similar intervention in the health facilities of Nepal can be effective in achieving the targeted objective of promoting vaginal delivery rates, especially in women belonging to Group 5 .

Caesarean section rates in single breech pregnancies in this study were very high $(>65 \%)$ and this could be due to the fact that as breech pregnancy is considered as an abnormal condition, the pregnant women may opt to receive a CS. The evidence, however, suggests that breech pregnancy is not linked to major complications, ${ }^{28}$ and vaginal delivery is advisable for breech pregnancy too. ${ }^{29}$

The authors acknowledge that this study has a few limitations. Firstly, this study analyzed a sample of women undergoing delivery service within the duration of one year. Ideally, a multiyear study would provide comprehensive knowledge on the CS rates and would present an understanding of the trend in CS rates over time. Secondly, the women that were studied were enrolled from a single health facility, so the representativeness of the study findings to other parts of the country remains doubtful. Despite these limitations, it is expected that the findings of this study provide evidence for targeted interventions for high-risk populations and baseline information for cross-country comparison in future studies.

\section{CONCLUSION}

The CS rate in Lumbini Zonal Hospital was far higher than the suggested optimum CS levels. Evidence of the high prevalence of CS and the concentration of CS in certain obstetric populations, as identified by this study, should be taken into consideration while formulating initiatives to direct public policies for the management of CSs. This study suggests further research be undertaken such as a retrospective analysis of CS rates for multiple years to identify trends. Developing risk profiles of women at high-risk of CS serves to provide evidence for devising timely interventions to limit CS rates for medically unwarranted conditions.

\section{ACKNOWLEDGMENTS}

The research team would like to thank the Lumbini Zonal Hospital team for the support provided during the study. The authors would like to thank Alisha Bhari and Kusum Thapa for helping with data collection. The authors also thank Parash Mani Bhandari for his support in writing this article.

\section{ETHICS APPROVAL AND CONSENT TO PARTICIPATE}

This study was approved by the National Health Research Council Kathmandu, Nepal.

\section{FUNDING}

This study did not receive any external funding.

\section{AUTHORS CONTRIBUTIONS}

BG and SDA conceptualized this study. BG, VPS, LB and KP ana- 
lyzed the data. BG prepared the first draft of the manuscript. VPS and BBR supervised this study and contributed to the revision of the draft manuscript. MJ assisted with manuscript review and revision. All the authors approved final manuscript prior to submission for publication.

\section{CONFLICTS OF INTEREST}

The authors declare that they have no conflicts of interest.

\section{REFERENCES}

1. The World Bank. Birth rate, crude (per 1,000 people). 2015. Web site. https://data.worldbank.org/indicator/SP.DYN.CBRT. IN. Accessed April 17, 2018.

2. Molina G, Weiser TG, Lipsitz SR, Esquivel MM, Uribe-Leitz T, Azad T, et al. Relationship between cesarean delivery rate and maternal and neonatal mortality. JAMA. 2015; 314(21): 2263-2270. doi: 10.1001/jama.2015.15553

3. Keag OE, Norman JE, Stock SJ. Long-term risks and benefits associated with cesarean delivery for mother, baby, and subsequent pregnancies: Systematic review and meta-analysis. PLoS Med. 2018; 15(1): e1002494. doi: 10.1371/journal.pmed.1002494

4. Hannah ME, Hannah WJ, Hewson SA, Hodnett ED, Saigal S, Willan AR. Planned caesarean section versus planned vaginal birth for breech presentation at term: A randomised multicentre trial. Term Breech Trial Collaborative Group. Lancet. 2000; 356(9239): 1375-1383. doi: 10.1016/s0140-6736(00)02840-3

5. Betran AP, Torloni MR, Zhang J, Ye J, Mikolajczyk R, DeneuxTharaux $\mathrm{C}$, et al. What is the optimal rate of caesarean section at population level? A systematic review of ecologic studies. Reprod Health. 2015; 12: 57. doi: 10.1186/s12978-015-0043-6

6. Ronsmans C, De Brouwere V, Dubourg D, Dieltiens G. Measuring the need for life-saving obstetric surgery in developing countries. BJOG. 2004; 111(10): 1027-1030. doi: 10.1111/j.14710528.2004.00247.x

7. Betran AP, Merialdi M, Lauer JA, Bing-Shun W, Thomas J, Van Look P, et al. Rates of caesarean section: analysis of global, regional and national estimates. Paediatr Perinat Epidemiol. 2007; 21(2): 98-113. doi: 10.1111/j.1365-3016.2007.00786.x

8. Shearer EL. Cesarean section: Medical benefits and costs. Soc Sci Med. 1993; 37(10): 1223-1231. doi: 10.1016/0277-9536(93)90334-z

9. Souza JP, Gulmezoglu A, Lumbiganon P, Laopaiboon M, Carroli G, Fawole B, et al. Caesarean section without medical indications is associated with an increased risk of adverse short-term maternal outcomes: The 2004-2008 WHO Global Survey on Maternal and Perinatal Health. BMC Med. 2010; 8: 71. doi: 10.1186/1741-7015$8-71$

10. Appropriate technology following birth. Lancet. 1986; 2(8520):
$1387-1388$.

11. Ye J, Betran AP, Guerrero Vela M, Souza JP, Zhang J, et al. Searching for the optimal rate of medically necessary cesarean delivery. Birth. 2014; 41(3): 237-244. doi: 10.1111/birt.12104

12. Cavallaro FL, Cresswell JA, Va Franca G, Victora CG, Jd Barros A, Ronsmans C, et al. Trends in caesarean delivery by country and wealth quintile: Cross-sectional surveys in southern Asia and sub-Saharan Africa. Bull World Health Organ. 2013; 91(12): 914-22d. doi: 10.2471/BLT.13.117598

13. Prasad A, Bhandari G, Saha R. Profile of caesarean section at Kathmandu Medical College. J Nepal Health Res Counc. 2017; 15(2): 111-113. doi: 10.3126/jnhrc.v15i2.18165

14. Torloni MR, Betran AP, Souza JP, Widmer M, Allen T, Gulmezoglu M, et al. Classifications for cesarean section: A systematic review. PLoS One. 2011; 6(1): e14566. doi: 10.1371/journal. pone.0014566

15. FIGO Working Group on Challenges in Care of Mothers and Infants during Labour and Delivery. Best practice advice on the 10-group classification system for cesarean deliveries. Int J Gynaecol Obstet. 2016; 135: 232-233. doi: 10.1016/j.ijgo.2016.08.001

16. World Health Organization (WHO). WHO Statement on Caesarean Section Rates: WHO/RHR/15.02, 2015. Web site. https:// www.who.int/reproductivehealth/publications/maternal_perinatal_health/cs-statement/en/. Accessed August 31, 2020.

17. Amatya A, Paudel R, Poudyal A, Wagle RR, Singh M, Thapa $\mathrm{S}$, et al. Examining stratified cesarean section rates using Robson classification system at Tribhuvan University Teaching Hospital. $J$ Nepal Health Res Counc. 2013; 11(25): 255-258.

18. Neuman M, Alcock G, Azad K, Kuddus A, Osrin D, More NS, et al. Prevalence and determinants of caesarean section in private and public health facilities in underserved South Asian communities: Cross-sectional analysis of data from Bangladesh, India and Nepal. BMJ Open. 2014; 4(12): e005982. doi: 10.1136/bmjopen-2014-005982

19. Betran AP, Ye J, Moller A-B, Zhang J, Gülmezoglu AM, Torloni MR. The increasing trend in caesarean section rates: Global, regional and national estimates: 1990-2014. PLoS One. 2016; 11(2): e0148343. doi: 10.1371/journal.pone.0148343

20. Kozhimannil KB, Law MR, Virnig BA. Cesarean delivery rates vary tenfold among US hospitals; reducing variation may address quality and cost issues. Health Aff (Millwood). 2013; 32(3): 527-535. doi: $10.1377 /$ hlthaff.2012.1030

21. Edmonds JK, O'Hara M, Clarke SP, Shah NT. Variation in cesarean birth rates by labor and delivery nurses. J Obstet Gynecol Neonatal Nurs. 2017; 46(4): 486-493. doi: 10.1016/j.jogn.2017.03.009 
22. Delbaere I, Cammu H, Martens E, Tency I, Martens G, Temmerman M. Limiting the caesarean section rate in low risk pregnancies is key to lowering the trend of increased abdominal deliveries: An observational study. BMC Pregnancy Childbirth. 2012; 12: 3. doi: 10.1186/1471-2393-12-3

23. Kennare R, Tucker G, Heard A, Chan A. Risks of adverse outcomes in the next birth after a first cesarean delivery. Obstet Gynecol. 2007; 109(2 Pt 1): 270-276. doi: 10.1097/01. AOG.0000250469.23047.73

24. Brennan DJ, Robson MS, Murphy M, O'Herlihy C. Comparative analysis of international cesarean delivery rates using 10-group classification identifies significant variation in spontaneous labor. Am J Obstet Gynecol. 2009; 201(3): 308.e1-e8. doi: 10.1016/j. ajog.2009.06.021

25. Royal College of Obstetricians and Gynaecologists. Birth After Previous Caesarean Birth. RCOG Green-top Guideline No 45, 2015. Web site. https://www.rcog.org.uk/en/guidelines-researchservices/guidelines/gtg45/. Accessed August 31, 2020.
26. Rossi AC, D'Addario V. Maternal morbidity following a trial of labor after cesarean section vs elective repeat cesarean delivery: A systematic review with metaanalysis. Am J Obstet Gynecol. 2008; 199(3): 224-231. doi: 10.1016/j.ajog.2008.04.025

27. Gardner K, Henry A, Thou S, Davis G, Miller T. Improving VBAC rates: The combined impact of two management strategies. Aust N Z J Obstet Gynaecol. 2014; 54(4): 327-332. doi: 10.1111/ ajo.12229

28. Vistad I, Cvancarova M, Hustad BL, Henriksen T. Vaginal breech delivery: Results of a prospective registration study. BMC Pregnancy Childbirth. 2013; 13: 153. doi: 10.1186/1471-2393-13-153

29. Hannah ME, Whyte H, Hannah WJ, Hewson S, Amankwah K, Cheng $\mathrm{M}$, et al. Maternal outcomes at 2 years after planned cesarean section versus planned vaginal birth for breech presentation at term: The international randomized Term Breech Trial. Am J Obstet Gynecol. 2004; 191(3): 917-927. doi: 10.1016/j.ajog.2004.08.004 